\section{LESSON 89}

Headings

Type this article exactly as it appears and write in the instructions. Keep the sheet for reference.

MARGINS: Pica, 10-72; Elite, 20-82.

PAPER: A4

Centre the title and sub-title over the typing line.

Some teachers ask for six spaces when using Elite type.

This style is used for numbered paragraphs as a rule. The indent can be one, two or three spaces.

A full stop is not necessary after a heading unless the last word is abbreviated.

Paragraph headings can be typed at the margin using the fully-blocked style.

UNIT 23
DISPLAY IN TYPING ARTICLES

A Practical Guide

The titte

The sub-title

In Lessons 16 and 18 you learned about the various kinds of paragraphs. These styles enable you to show off the work to better advantage and make it easier to follow.

\section{PARAGRAPHS shoulde heading}

Blocked paragraphs are those which start flush on the left-hand margin like this one.

Indented paragraphs are those in which the first line starts five spaces in from the margin, while all other lines in the paragraph start on the left-hand margin.

Hanging paragraphs are those in which the first line starts on the margin but all other lines are indented two spaces in from the margin. This is a hanging paragraph.

It is usual to leave a blank line between any paragraphs.

HEADINGS Paragraph heuding

The title is the main heading and is centred over the typing line and is usually typed in capital letters. In this exercise the main heading is "DISPLAY IN TYPING ARTICLES" and could be typed in spaced capitals if you so wished. In Lesson 40 you learned that you must leave three spaces between each word if you use spaced capitals.

The sub-title tells you more about the material which follows and adds to the information given by the heading. The sub-title to this exercise is "A Practical Guide" and is centred under the main title and is not typed in capital letters. There is no need to have a sub-title unless it serves a purpose. Both main and sub-titles may be underscored if you wish.

Shoulder headings break up the work into main sections and they are typed in closed capital letters on the left-hand margin. After a shoulder heading you must turn up two single line spaces to leave one blank line between it and the paragraph. Underscore shoulder headings, but not any following punctuation marks. The shoulder headings in this exercise are "PARAGRAPHS" and "HEADINGS."

Paragraph headings twll you more about what is in each paragraph and they are underscored, though again do not underscore any following punctuation marks. There are several paragraph headings in this exercise and they form part of the paragraph.

\section{LESSON 89}

